\section{Síndrome de meningitis y retención urinaria}

\author{
LUIS CARTIER R. ${ }^{1,2}$, FERNANDO HANSEN B. ${ }^{1}$ \\ Meningitis-retention syndrome. \\ Report of one case
}

The Meningitis-Retention Syndrome associates aseptic meningitis and neurogenic bladder, with a vesical dysfunction that outlasts meningitis widely. Urodynamic assessment shows a detrusor palsy with normal function of the external sphincter. We report a 24-year-old male admitted for headache, fever, myalgias and acute urinary retention, which was diagnosed as a urinary tract infection. Worsening of symptoms and slight meningeal signs prompted for a lumbar puncture that yielded a cerebrospinal fluid with 94 lymphocytes, in which etiological evaluation was inconclusive. Meningeal syndrome and myalgia subsided by the fifth day, while urinary retention persisted. A magnetic resonance imaging of the brain and spinal cord done at the fifth day, showed high intensity signals in basal ganglia and central spinal cord, not altered by contrast. These images disappeared in the imaging control performed two months later. Bladder dysfunction lasted at least until the second month of follow up.

(Rev Med Chile 2014; 142: 1607-1611)

Key words: Ganglia, parasympathetic; Meningitis; Urinary bladder, neurogenic. 'Servicio de Neurología, Hospital
del Salvador, Santiago, Chile.
'Departamento de Ciencias
Neurológicas, Hospital del
Salvador, Facultad de Medicina,
Universidad de Chile, Santiago,
Chile.
No se contó con fuentes
de apoyo financiero para la
redacción de este artículo.
Recibido el 22 de noviembre de
2013, aceptado el 22 de octubre
de 2014.
Correspondencia a:
Dr. Luis Cartier R.
Departamento de Ciencias
Neurológicas, Facultad de
Medicina Campus Oriente,
Universidad de Chile.
Avenida Salvador 364,
Providencia, Santiago.
Teléfono: 6-6489936
Icartier@med.uchile.cl
$\mathrm{E}$ compromiso vesical no forma parte del síndrome meníngeo y es un hallazgo infrecuente en pacientes con meningitis. La aparición en el año 2005 del concepto 'síndrome meningitis-retención' (SMR) acuñado por Sakakibara y colaboradores, definió una entidad que involucraba una inhabitual asociación de meningitis y vejiga neurogénica, en la que después de desaparecido el cuadro meníngeo la disfunción vesical se prolonga como enfermedad independiente por varias semanas y en ausencia de etiopatogenia identificable ${ }^{1}$. La urodinamia, en la mayoría de estos pacientes, ha establecido la ausencia de actividad en el detrusor y la conservación funcional del esfínter externo de la vejiga.

Otro síndrome que también expresa una retención urinaria aguda como el SMR y con el que se puede confundir es el síndrome de Elsberg. Sin embargo, este último no se acompaña de meningitis, el daño involucra atonía vesical y del esfínter externo, que es la expresión de una poliradiculopatía sacra vinculada a una infección por el virus Herpes Simplex $2^{2}$.

La vejiga es un órgano hueco destinado a la acumulación de orina, mientras el esfínter externo se mantiene ocluido y el músculo detrusor está en reposo; al llenarse, la vejiga se distiende y el deseo miccional surge debido a la contracción automática del músculo detrusor como consecuencia del aumento de presión intravesical, condición informada a la médula por las fibras propioceptivas que activan la respuesta del detrusor. En la emisión de orina se asocia: la contracción del detrusor, la relajación voluntaria del esfínter externo, y la contracción voluntaria de la prensa abdominal que mantiene una presión intravesical conveniente ${ }^{3}$.

La compleja inervación del tracto urinario 
asocia fibras nerviosas autonómicas, sensitivas y motoras que actúan secuencialmente como hemos visto. Las fibras motoras parasimpáticas tienen su nacimiento en la columna intermedio lateral de la sustancia gris de la médula sacra (S2 a S4), que origina fibras preganglionares colinérgicas que terminan en los ganglios del plexo pélvico, desde donde parte la inervación del músculo detrusor y de la superficie externa de la vejiga ${ }^{4}$. Las fibras simpáticas surgen por las raíces anteriores de la médula dorsal (T10 a T12) y se incorporan a los nervios esplácnicos hasta llegar al ganglio mesentérico inferior, origen de los nervios hipogástricos que van a constituir el plexo sacro que inerva los receptores $\beta$-adrenérgicos del techo de la vejiga, el trígono y del esfínter interno autonómico. Las fibras somatomotoras nacen en el núcleo de Onuf ubicado en el asta anterior de la médula sacra (S2 a S4) que forman parte de los nervios pudendos que van a inervar los esfínteres voluntarios de la uretra y el ano. El sistema sensitivo está provisto por fibras mielinizadas tipo A, que nacen de los receptores propioseptivos en la pared vesical, perciben y trasmiten la distensión de la vejiga; y de fibras $C$ amielínicas que desde células uroteliales trasmiten la sensibilidad de la mucosa vesical y llegan a la médula en los nervios pudendos ${ }^{4}$. Por ello la vejiga es sensible al dolor y a la presión.

Presentamos un paciente, que en el contexto de una meningitis aséptica benigna de corta duración, desarrolló una vejiga neurogénica que duró meses.

\section{Caso clínico}

Se presenta un hombre de 24 años procedente de Curicó con el antecedente de episodios migrañosos en el último año. En noviembre del año 2012 se le diagnosticó otitis media aguda y fue tratada con antibióticos por siete días, con buena evolución. Quince días más tarde inició malestar general, mialgias, cefalea holocránea y fiebre que lo obligó a consultar. Sus síntomas se interpretaron inicialmente como un cuadro gripal, pero la observación de una repentina retención urinaria reorientó el diagnóstico hacia una infección urinaria. Se instaló sonda Foley y se inició terapia antibiótica que no mejoró el cuadro, incluso al segundo día los familiares notaron compromiso de la vigilancia, que asociado a la debilidad gene- ralizada de las extremidades los hizo concurrir al Servicio de Urgencia del Hospital del Salvador el día 1 de diciembre de 2012. Ingresó orientado, aunque intelectualmente lento, con cefalea y, además, intensas mialgias que generaban impotencia funcional; reflejos osteotendíneos presentes, reflejos plantares flexores, sin déficits sensitivos y el fondo de ojo era normal. Tomografía cerebral (TC) y tomografía de columna dorsal no mostraron alteraciones. La punción lumbar dio salida a un líquido cefalorraquídeo (LCR) claro con 47 linfocitos, con glucosa y proteínas normales. Se inició tratamiento con ceftriaxona y aciclovir con el diagnóstico de meningitis. Al segundo día de hospitalización estaba vigil, activo, mantenía cierto dolor cervical y se movía con dificultad por las mialgias. Se repitió el LCR que mostró 94 linfocitos, con albúmina y glucosa normales, el estudio de Gram fue negativo; VDRL, ADA y tinta china, así como la serología para VHB, VHC, VIH, HTLV1 fueron no reactivas, hemocultivos y cultivo de LCR no logró identificación ni aislamiento de gérmenes. Evolucionó afebril y con parámetros inflamatorios bajos. Al cuarto día de hospitalización había mejorado el estado general, desaparecido las mialgias y la CK era de 28. Sólo persistía la retención urinaria.

Por serología se investigó el virus Herpes 6, Enterovirus, Citomegalovirus, virus Varicela Zoster, Parvovirus (IgM e IgG) y Listeria que resultaron negativos. La búsqueda del Mycoplasma mostró una Ig G positiva y una Ig M negativa. La resonancia magnética (Figura 1) definió zonas de hiperintensidad en el núcleo caudado y putamen, sin refuerzo con la administración de contraste endovenoso, la médula espinal también presentaba hiperintensidades en el centro de la médula desde cervical a lumbar, que no se reforzaron con el medio de contraste. El estudio de bandas oligoclonales fue negativo. Los potenciales evocados visuales fueron normales.

El 18 de diciembre de 2012 se realizó control de LCR que mostró un líquido claro, con proteínas $0,19 \mathrm{~g} / \mathrm{L}$, glucosa $0,58 \mathrm{~g} / \mathrm{L}$, leucocitos 1,6 $\mathrm{mm}^{3}$. Fue dado de alta en buenas condiciones y con una persistente vejiga neurogénica. Concurrió el 15 de enero a control de RM, aún con sonda vesical. El estudio de imágenes estableció la casi desaparición de las imágenes hiperintensas cerebrales y la regresión completa de las imágenes en la médula. 

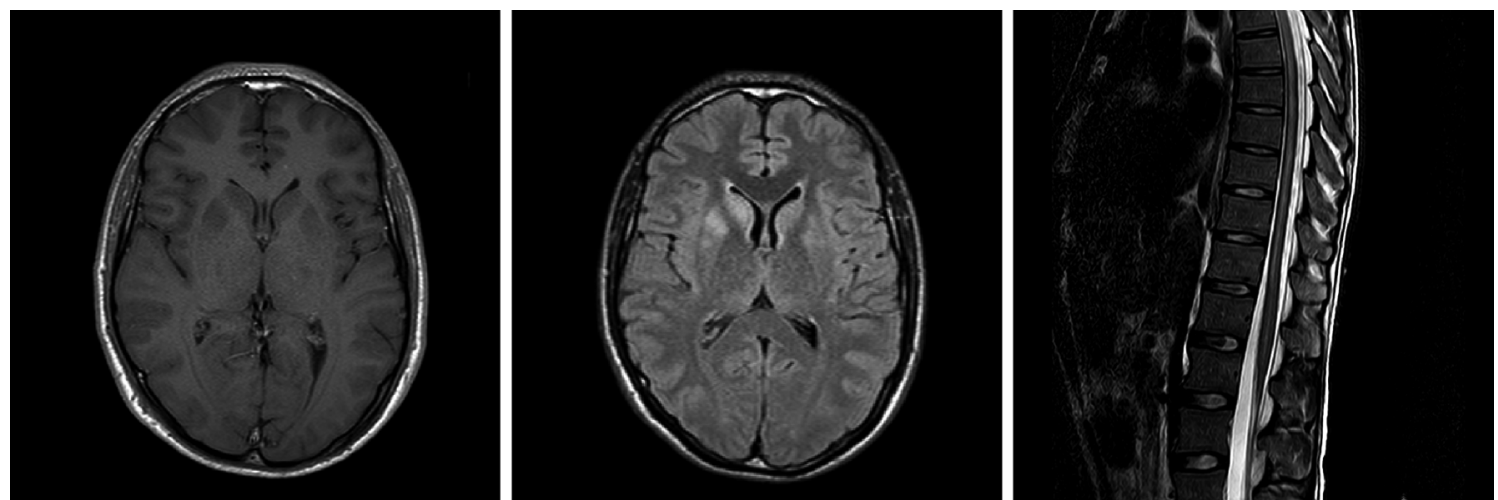

Figura 1. Resonancia magnética tomada al quinto día de hospitalización. T1 con contraste y FLAIR de cerebro, médula espinal T2. Se observan zonas de hiperintensidad en los núcleos caudados y putamen e imágenes con cierta hiperintensidad en las regiones centro medular, que no se refuerzan con el medio de contraste.
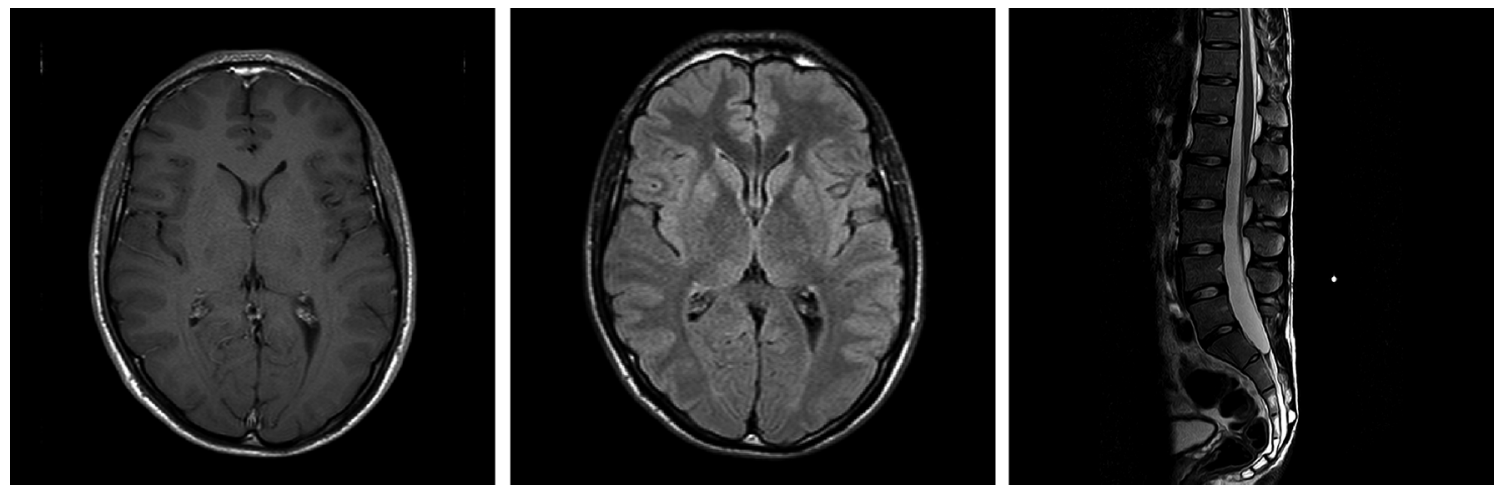

Figura 2. Resonancia magnética, $\mathrm{t} 1$ con contraste y FLAIR de cerebro, médula espinal t2, tomadas al mes y medio de hospitalización. Muestran una significativa disminución de la intensidad de señal en los núcleos de la base y la normalización de la señal en la médula espinal.

\section{Discusión}

Se ha presentado un paciente de 24 años que en el contexto de una meningitis aséptica de corta duración, desarrolló una retención urinaria que se prolongó por más de ocho semanas desde su inicio. Casos similares han sido reportados desde los años ochenta en pacientes japoneses, algunos de ellos consignados en la Tabla 1. Se ha observado que el síndrome meningitis-retención afecta con mayor frecuencia a jóvenes y cursa con líquido cefalorraquídeo claro, pleocitosis de predominio linfocitario, sin aumento de la albumina, ni baja en la glucosa. El comienzo del síndrome de retención urinaria coincide con la instalación de la meningitis ${ }^{1}$.
Es necesario destacar en nuestro paciente, la presencia de intensos dolores musculares desde los primeros días de la enfermedad, que lo llevaron a una impotencia funcional y opacaron el síndrome meníngeo. La CK se mantuvo normal. Estas mialgias no han sido descritas en otros SMR. También en este paciente se observó algún grado de confusión fugaz, que concuerda con lo observado en pacientes de más edad, seguramente en relación al síndrome meníngeo (Tabla 1).

Las imágenes hiperintensas de la RM cerebral de nuestro paciente, observadas días después del comienzo de la meningitis crearon cierta confusión respecto a la patogenia del cuadro, aunque no hubo correlato clínico-imagenológico y el paciente en el momento que se hizo la resonancia estaba 


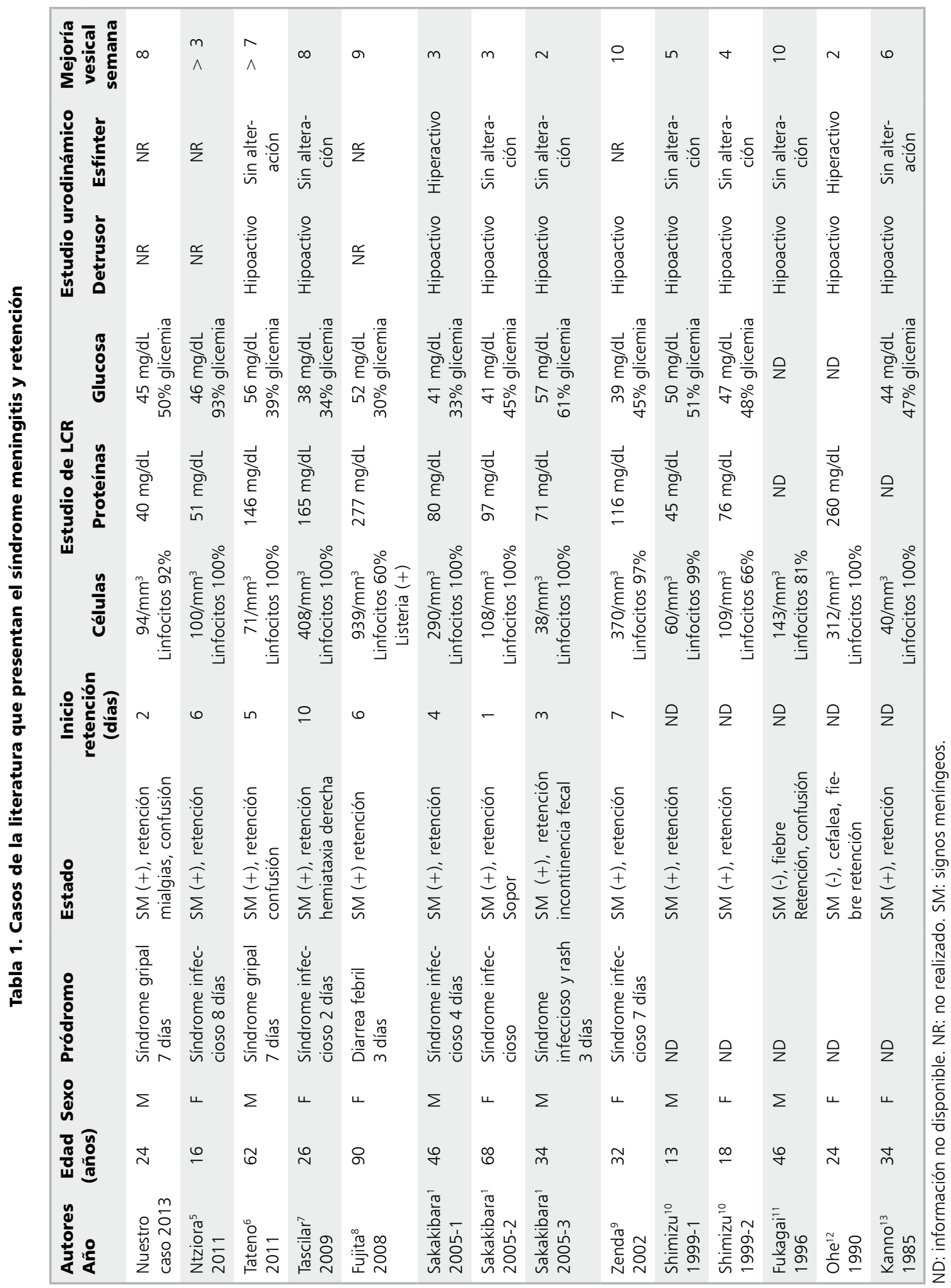


prácticamente asintomático, salvo el compromiso de la vejiga. Circunstancialmente hemos observado hiperintensidades fugaces en los núcleos basales asociadas a cuadros presuntivamente virales, que al igual que en este caso no se acompañaron de una clínica concordante.

Sakakibara y colaboradores recientemente han propuesto que el SMR que describieron podría ser interpretado como una variante de la encefalomielitis aguda diseminada (Acute Disseminated Encephalomyelitis (ADEM)), aunque ellos no encontraron cambios encefalopáticos o en la RM de sus pacientes que orientaran a dicha hipótesis ${ }^{1}$. Tampoco se consignan alteraciones imagenológicas en ningún de los casos de SRM descritos por varios autores, algunos incluidos en la Tabla 1. Como se sabe, las ADEM desarrollan una definida encefalopatía asociadas a imágenes patológicas en la RM de cerebro ${ }^{14}$. En nuestro paciente la presencia de imágenes en la RM sospechosas de un compromiso encefálico, aunque sin clínica, hizo temer en algún momento la hipótesis sugerida por Sakakibara. Sin embargo, la rápida evolución del SMR en ausencia de síntomas de compromiso central o periférico, salvo la ganglionopatía parasimpática, apunta a un síndrome autonómico-meníngeo, más que a un síndrome frustro o variante de ADEM.

La parálisis del detrusor asociada a la preservación del esfínter vesical ha sido el hallazgo de la urodinamia en la mayoría de los pacientes con SMR. Ello sugiere una inhibición selectiva del sistema motor parasimpático (detrusor) y la conservación funcional tanto del sistema nervioso central, como del sistema nervioso periférico.

Ha resultado interesante haber tenido la oportunidad de comunicar este síndrome de meningitis-retención que se manifiesta como un cuadro relativamente benigno y que puede pasar inadvertido o ser mal interpretado. Es una enfermedad que vincula una meningitis y una ganglionopatía.

\section{Referencias}

1. Sakakibara R, Uchiyama T, Liu Z, Yamamoto T, Ito T, Uzawa A, et al. Meningitis-retention syndrome. An unrecognized clinical condition. J Neurol 2005; 252 (12):
1495-9.

2. Eberhardt O, Küker W, Dichgans J, Weller M. HSV-2 sacral radiculitis (Elsberg syndrome). Neurology 2004; 63 (4): 758-9.

3. Chapple C. Overview on the lower urinary tract. En Andersson KE, Michel MC, Editores, Urinary Tract, Handbook of Experimental Pharmacology 202. Berlín, Alemania: Springer-Verlag 2011; p. 1-14.

4. Beckel JM, Holstege G. Neuroanatomy of the lower urinary tract. En Andersson KE, Michel MC, Editores, Urinary Tract, Handbook of Experimental Pharmacology 202. Berlín, Alemania: Springer-Verlag 2011; p. 99-116.

5. Ntziora F, Alevizopoulos A, Konstantopoulos K, Kanellopoulou S, Bougas D, Stravodimos K. Aseptic meningitis with urinary retention: a case report. Case Rep Med 2011; Volumen 2011, artículo 741621. DOI:10.1155/2011/741621. Disponible en http://www. hindawi.com/crim/medicine/2011/741621/ [Consultado el 13 de noviembre de 2013].

6. Tateno F, Sakakibara R, Sugiyama M, Takahashi O, Kishi $\mathrm{M}$, Ogawa E, et al. Meningitis-retention syndrome: first case of urodynamic follow-up. Intern Med 2011; 50 (2): 1329-32.

7. Tascilar N, Aydemir H, Emre U, Unal A, Atasoy HT, Ekem S. Unusual combination of reversible splenial lesión and meningitis-retention syndrome in aseptic meningomyelitis. Clinics 2009; 64 (9): 932-7.

8. Fujita K, Tanaka T, Kono S, Narai H, Omori N, Manabe $\mathrm{Y}$, et al. Urinary Retention Secondary to Listeria Meningitis. Inter Med 2008; 47 (12): 1129-31.

9. Zenda T, Soma R, Muramoto H, Hayase H, Orito M, Okada $\mathrm{T}$, et al. Acute urinary retention as an unusual manifestation of aseptic meningitis. Internal Medicine 2002; 41 (5): 392-4.

10. Shimizu Y, Yamamoto S, Inoue K, Nakamura Y, Tokonami F, Aii H, et al. Two cases of urinary retention secondary to aseptic meningitis. Hinyokika Kiyo 1999; 45 (6): 435-7.

11. Fukagai T, Ishihara M, Funabashi K, Naitoh Y, Murayama K. A case of urinary retention secondary to aseptic meningitis. Rinshou Hinyoukika 1996; 50: 67-70.

12. Ohe $\mathrm{C}$, Ohashi Y. A case of urinary retention secondary to aseptic meningitis. Rinshou Hinyoukika 1990; 44: 911-3.

13. Kanno R, Yokoyama J, Takagi Z. Aseptic meningitis associated with urinary retention. Annu Rep Ohara Hosp 1985; 28: 51-4.

14. Krupp LB, Banwell B, Tenembaum S, y the International Pediatric Multiple Sclerosis Study Group. Consensus definitions proposed for pediatric multiple sclerosis and related disorders. Neurology 2007; 68 (Suppl 2): S7-S12. 